\title{
COMBINED DRUG TREATMENT OF TUBERCULOSIS. III. CLINI- CAL APPLICATION OF THE PRINCIPLES OF APPROPRIATE AND ADEQUATE CHEMOTHERAPY TO THE TREATMENT OF PULMONARY TUBERCULOSIS
}

\author{
By WILLIAM F. RUSSELL, JR., IRVING KASS, ANGELINE D. HEATON, \\ SIDNEY H. DRESSLER AND GARDNER MIDDLEBROOK
}

\author{
(From the Department of Medicine and Research and Laboratories, National Jewish Hospital \\ at Denver, and the Departments of Medicine and Microbiology, University of \\ Colorado School of Medicine, Denver, Colo.)
}

(Submitted for publication September 10, 1958; accepted February 23, 1959)

Microbiologic investigation of the prevention of emergence of mutant populations of tubercle bacilli resistant to streptomycin and isoniazid emphasized the fact that adequate concentrations of each of these two appropriate drugs were necessary (1). Delivery of such concentrations of isoniazid to the multiplying parasites can be estimated by microbiologic assay (2-4). Antimicrobially-active serum streptomycin assayed by a similar microbiologic method confirmed that there were also probably significant variations between individuals in serum levels of this drug as well. These observations suggested that conventional dosages of these drugs could not be relied upon to insure the delivery in vivo of sterilizing concentrations of each agent to physiologically-susceptible tubercle bacilli. The result of consideration of these principles was the formulation of a chemotherapeutic regimen combining high dosage of streptomycin with high dosage of isoniazid for all patients (5-7). The purpose of this report (the third of a series) is to present the results of clinical application of this approach to chemotherapy of pulmonary tuberculosis.

\section{METHODS AND MATERIALS}

A. Bacteriology. The bacteriologic studies were performed according to methods described elsewhere $(8,9)$. These routine studies consisted of Ziehl-Neelsen stained smears of the concentrated, digested sputum; the results were reported as the number of acid-fast rods seen per oil immersion field. The concentrated sediment of the digested sputum was then diluted according to the number of acid-fast rods seen on smear. When the smear revealed less than one acid-fast rod per oil immersion field, the concentrate was inoculated both undiluted and diluted $10^{-1}$. When the concentrate smear revealed one to 10 acid-fast rods per oil immersion field, the sediment was diluted $10^{-1}$ and $10^{-2}$. When the smear revealed more than 10 acid-fast rods per oil immersion field, the sediment was diluted $10^{-2}$ and $10^{-3}$ prior to inoculation of the culture plates. Every specimen was seeded on solid medium (1) containing no antimycobacterial drugs (the control), on the same medium containing streptomycin, $2.0 \mu \mathrm{g}$. per ml., and on the same medium containing isoniazid, $0.2 \mu \mathrm{g}$. per $\mathrm{ml}$. During the period covered in this study, a third direct routine drug-susceptibility test was performed. Prior to 1955, this third test was isoniazid, $10 \mu \mathrm{g}$. per ml. In 1955, pyrazinamide, $50 \mu \mathrm{g}$. per ml., was the test drug for some months. Since that time, paraaminosalicylic acid, $2.0 \mu \mathrm{g}$. per ml., has been used in this third susceptibility test.

The definition of drug-susceptibility employed in this report is as follows: A strain or population of tubercle bacilli is susceptible to the action of streptomycin or isoniazid if less than 1 per cent of those members yielding colonies on the control are able to grow and produce colonies on culture medium containing either streptomycin, $2.0 \mu \mathrm{g}$. per ml. or isoniazid, $0.2 \mu \mathrm{g}$. per $\mathrm{ml}$. Such bacterial populations were considered significantly drug-resistant if more than 1 per cent was recovered on medium containing streptomycin or isoniazid in these concentrations.

Catalase testing, using 15 per cent hydrogen peroxide in 5 per cent Tween ${ }^{\circledR} 80$, was performed routinely on the control culture $(8,9)$. As employed, this test provides a crude estimate of the moderate catalase activity of typical tubercle bacilli, the high activity of the so-called "yellow" bacilli, and the reduced or absent activity of catalase-deficient, isoniazid-resistant mutants.

The culture plates were incubated under 2 to 5 per cent carbon dioxide in air at $36^{\circ} \mathrm{C}$. for 21 days (10). The results of culture, drug-susceptibility testing, and catalase testing became available for clinical use within 25 days following collection of the sputum. This provided a unique opportunity for the selection of the appropriate agents and for close monitoring of the bacteriologic response of the patient.

Bacteriologic conversion of the sputum to negative was defined to have occurred when three consecutive sputum specimens collected at monthly intervals were found to be negative both on smear of the concentrate and on culture, and no subsequent positive sputum studies were encountered. The date of conversion was that of the first specimen which was negative on both smear and culture. This 
TABLE I

Cumulative bacteriologic conversion (chemotherapy alone)

\begin{tabular}{ccccc}
\hline Group & Total & $\begin{array}{c}\text { Negative at } \\
\text { 1-4 mos./total }\end{array}$ & $\begin{array}{c}\text { Negative at } \\
5-8 \text { mos./total }\end{array}$ & $\begin{array}{c}\text { Negative at } \\
9-12 \text { mos./total }\end{array}$ \\
\hline I & $(153)$ & $127 / 153$ & $152 / 153$ & $141 / 142^{*}$ \\
II & $(39)^{*}$ & $12 / 39^{*}$ & $15 / 36^{*}$ & $16 / 34^{*}$ \\
III & $(117)^{*}$ & $11 / 117^{*}$ & $13 / 105^{*}$ & $14 / 82^{*}$
\end{tabular}

* Losses due to early discharge or conversion concomitant with surgery or collapse procedures.

has been reported as occurring in the one to four month period (from Day 1 through Day 120 of chemotherapy), the five to eight month period (from Day 121 through Day 240 of chemotherapy), the nine to 12 month period, and so forth. When sputum conversion occurred as the result of collapse procedures (pneumothorax, pneumoperitoneum or thoracoplasty) or resection surgery, the subject was eliminated from further bacteriologic statistical analysis; this accounts for some of the reduction in actual cases observed in Table I.

$B$. Roentgenography. Admission roentgenograms of the chest were interpreted according to the Diagnostic Standards of the National Tuberculosis Association, 1955 (11), with the following differences: 1) Cavities have been reported as single or multiple, and 2) cavity size has been reported as the greatest internal dimension of the largest single cavity. Thus, in some instances, moderately advanced disease has been reported here associated with a large cavity or with multiple small cavities the sum of the diameters of which would require designation as far ad- vanced by N.T.A. Standards. This modification was necessary because it seemed important to analyze the extent of disease separate from the cavity component.

$\mathrm{X}$-rays made during the one to four month period and the five to eight month period have been compared with the admission film in order to assess the response to treatment. Comparison roentgenograms were selected which were made near to the end of the period. However, when collapse procedures or resection surgery were employed, the film taken just prior to the procedure was used for the final comparison and no further $\mathrm{X}$-ray evaluation was made for these studies. This accounts for some of the reduction in total cases observed in Tables II and III.

Special roentgenographic studies, including tomography, were performed early during the admission of each patient, and were repeated as indicated.

C. Microbiologic assay for serum isoniazid. Estimation of the serum concentration of antimicrobially-active isoniazid has been an important part of the evaluation of our patients during most of the period covered in this study. Determinations were made by the microbiologic method in 280 of the patients being reported here $(12,13)$. These patients were divided into three categories on the basis of their serum levels of active isoniazid. Thus, 76 had levels less than $0.4 \mu \mathrm{g}$. per ml.; 94 had levels of 0.4 to $0.8 \mu \mathrm{g}$. per $\mathrm{ml}$; and 110 had levels in excess of $0.8 \mu \mathrm{g}$. per $\mathrm{ml}$. It has been estimated that a serum level of active isoniazid of $0.4 \mu \mathrm{g}$. or more per $\mathrm{ml}$. at six hours after one-half of the daily dose is adequate for optimal chemotherapeutic action (2).

When it was shown that concomitant administration of

TABLE II

General roentgenographic response to chemotherapy

\begin{tabular}{|c|c|c|c|c|c|c|c|c|}
\hline \multirow[b]{2}{*}{ Group } & \multicolumn{2}{|c|}{ Total } & \multicolumn{2}{|c|}{ Worse } & \multicolumn{2}{|c|}{$\begin{array}{l}\text { None-slight } \\
\text { improvement }\end{array}$} & \multicolumn{2}{|c|}{$\begin{array}{l}\text { Mod.-marked } \\
\text { improvement }\end{array}$} \\
\hline & $\begin{array}{c}1-4 \\
\text { mos. }\end{array}$ & $\begin{array}{c}5-8 \\
\text { mos. }\end{array}$ & $\begin{array}{c}1-4 \\
\text { mos. }\end{array}$ & $\begin{array}{l}5-8 \\
\text { mos. }\end{array}$ & $\begin{array}{c}1-4 \\
\text { mos. }\end{array}$ & $\begin{array}{c}5-8 \\
\text { mos. }\end{array}$ & $\begin{array}{c}1-4 \\
\text { mos. }\end{array}$ & $\begin{array}{c}5-8 \\
\text { mos. }\end{array}$ \\
\hline$\underset{\text { III }}{\text { I I }}$ & $\begin{array}{r}153 \\
40 \\
123\end{array}$ & $\begin{array}{r}153 \\
37^{*} \\
99^{*}\end{array}$ & $\begin{array}{l}1 \\
0 \\
3\end{array}$ & $\begin{array}{l}1 \\
2 \\
5\end{array}$ & $\begin{array}{r}83 \\
34 \\
116\end{array}$ & $\begin{array}{l}49 \\
23 \\
87\end{array}$ & $\begin{array}{r}69 \\
6 \\
4\end{array}$ & $\begin{array}{r}103 \\
12 \\
7\end{array}$ \\
\hline
\end{tabular}

* Losses due to collapse procedures and/or resection surgery.

TABLE III

Roentgenographic response of cavities to chemotherapy

\begin{tabular}{|c|c|c|c|c|c|c|c|c|c|c|}
\hline \multirow[b]{4}{*}{ Group } & & & \multicolumn{8}{|c|}{ Cavity status } \\
\hline & & & & & & & & & & \\
\hline & \multicolumn{2}{|c|}{ Total } & \multicolumn{2}{|c|}{ Open } & \multicolumn{2}{|c|}{ Filled } & \multicolumn{2}{|c|}{ Indefinite } & \multicolumn{2}{|c|}{ Lost to view } \\
\hline & $1-4$ & $5-8$ & $1-4$ & $5-8$ & $1-4$ & $5-8$ & $1-4$ & $5-8$ & $1-4$ & $5-8$ \\
\hline$\underset{\mathbf{I I}}{\mathbf{I}}$ & $\begin{array}{r}145 \\
40 \\
118^{*}\end{array}$ & $\begin{array}{r}145 \\
38^{*} \\
94^{*}\end{array}$ & $\begin{array}{r}117 \\
37 \\
112\end{array}$ & $\begin{array}{l}71 \\
30 \\
79\end{array}$ & $\begin{array}{l}3 \\
0 \\
3\end{array}$ & $\begin{array}{r}12 \\
3 \\
9\end{array}$ & $\begin{array}{l}2 \\
2 \\
1\end{array}$ & $\begin{array}{r}11 \\
2 \\
1\end{array}$ & $\begin{array}{r}23 \\
1 \\
2\end{array}$ & $\begin{array}{r}51 \\
3 \\
5\end{array}$ \\
\hline
\end{tabular}

* Losses due to collapse procedures and/or resection surgery. 
TABLE IV

Criteria for selection of patients*

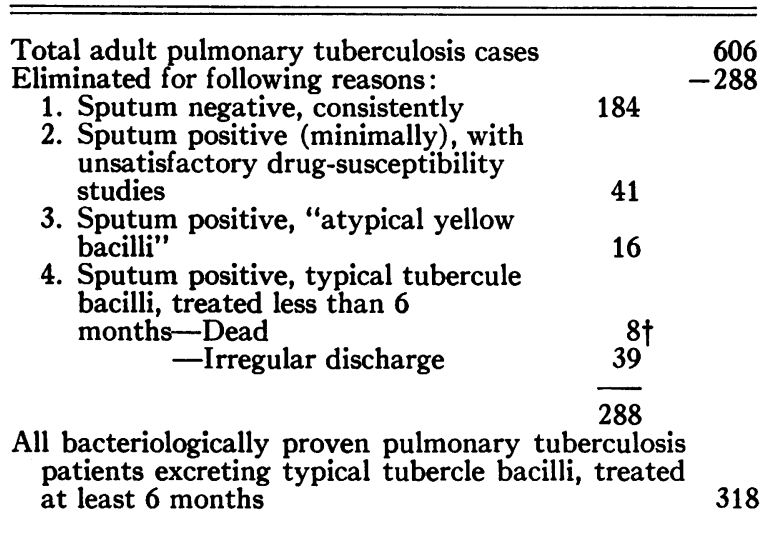

* October 1, 1954, to June 1, 1957.

$\dagger$ Five nontuberculous deaths; three surgical deaths, all excreting drug-resistant organisms.

para-aminosalicylic acid (or para-aminobenzoic acid) elevated the serum levels of active isoniazid, this drug (in the dosage of $12 \mathrm{Gm}$. NaPAS or NaPABA daily) was added to the basic regimen of those patients known to have levels less than $0.4 \mu \mathrm{g}$. per $\mathrm{ml}$. $(12,13)$. The specific purpose of adding either of these drugs to the basic regimen in these individuals was to elevate the serum level of active isoniazid.

D. Microbiologic assay for serum streptomycin. Serum levels of antimicrobially-active streptomycin have been determined in 48 of these patients. There were four who had levels less than $10 \mu \mathrm{g}$. per $\mathrm{ml}$.; 13 had levels of 10 $\mu \mathrm{g}$. per $\mathrm{ml}$.; 23 had levels of $20 \mu \mathrm{g}$. per ml.; and eight achieved levels in excess of $20 \mu \mathrm{g}$. per $\mathrm{ml}$. The microbiologic method used was a serial tube dilution technique employing an isoniazid-resistant strain of H37Rv. This method has yielded generally lower values than the filterpaper disc-agar diffusion method using a strain of $B$. subtilis (3). Limited correlation of chemotherapeutic response with streptomycin levels at six hours following a $20 \mathrm{mg}$. per $\mathrm{Kg}$. test dose suggested that patients who fail to achieve a level in excess of $20 \mu \mathrm{g}$. per $\mathrm{ml}$. were receiving what might prove to be insufficient dosage. Thus, in this study, several patients in Group I (see below) who had "adequate" isoniazid serum levels and had not converted to negative before 10 weeks after initiation of chemotherapy and who had streptomycin serum levels below $20 \mu \mathrm{g}$. per $\mathrm{ml}$. were given increased dosage of streptomycin up to $35 \mathrm{mg}$. per $\mathrm{Kg}$. per day.

E. Clinical material. Between October 1, 1954, and June 1,1957 , a total of 606 patients with the clinical diagnosis of pulmonary tuberculosis were admitted consecutively to the adult service of National Jewish Hospital at Denver (Table IV). Of these, 288 were considered unsuitable for bacteriologic evaluation of the high dosage regimen. Sputa from 184 of these 288 patients were consistently negative, and sputa from 41 were so infrequently and so slightly positive that drug-susceptibility tests were unsatisfactory. ${ }^{1}$ Sixteen patients were excreting "atypical yellow bacilli," Mycobacterium tuberculosis luciflavum (14). Of those patients excreting typical tubercle bacilli, eight were lost because of death (five nontuberculous deaths, and three surgical deaths; these latter were excreting drug-resistant tubercle bacilli), and 39 because of irregular discharge, after less than six months of treatment. This study is concerned with the results of high dosage chemotherapy of 318 adults admitted consecutively with bacteriologically-proven pulmonary tuberculosis, with typical tubercle bacilli recovered on sputum culture, and with treatment for at least six months.

On the basis of the results of drug-susceptibility testing of the populations of tubercle bacilli recovered from the admission sputa, these 318 patients have been divided

1 One of these patients became consistently sputumpositive with streptomycin-resistant, isoniazid-resistant, para-aminosalicylic acid-susceptible, catalase-negative tubercle bacilli in the sputum four months after admission and while on chemotherapy with isoniazid/para-aminosalicylic acid.

TABLE V

Background data on 318 patients grouped according to drug-susceptibility studies

\begin{tabular}{|c|c|c|c|c|c|c|c|}
\hline Group & Drug susc. & Sex & Number & $\begin{array}{c}\text { Average age } \\
(y r s .)\end{array}$ & Range & White & Nonwhite \\
\hline \multirow{2}{*}{ I } & \multirow{2}{*}{ SM-S/INH-S* } & $\mathbf{M}$ & 94 & 40.5 & $(15-68)$ & 80 & 14 \\
\hline & & $\mathbf{F}$ & 59 & 37.6 & $(17-80)$ & 50 & 9 \\
\hline \multirow{2}{*}{ II } & SM-R/INH-S & $\mathbf{M}$ & 26 & 41.5 & $(21-70)$ & 24 & 2 \\
\hline & SM-S/INH-R $†$ & $\mathbf{F}$ & 14 & 28.8 & $(17-56)$ & 14 & 0 \\
\hline \multirow{2}{*}{ III } & \multirow{2}{*}{$\mathrm{SM}-\mathrm{R} / \mathrm{INH}-\mathrm{R}$} & $\mathbf{M}$ & 71 & 44.6 & $(20-68)$ & 67 & 4 \\
\hline & & $\mathbf{F}$ & 54 & 38.6 & $(20-69)$ & 47 & 7 \\
\hline
\end{tabular}


TABLE VI

Comparative roentgenographic characteristics

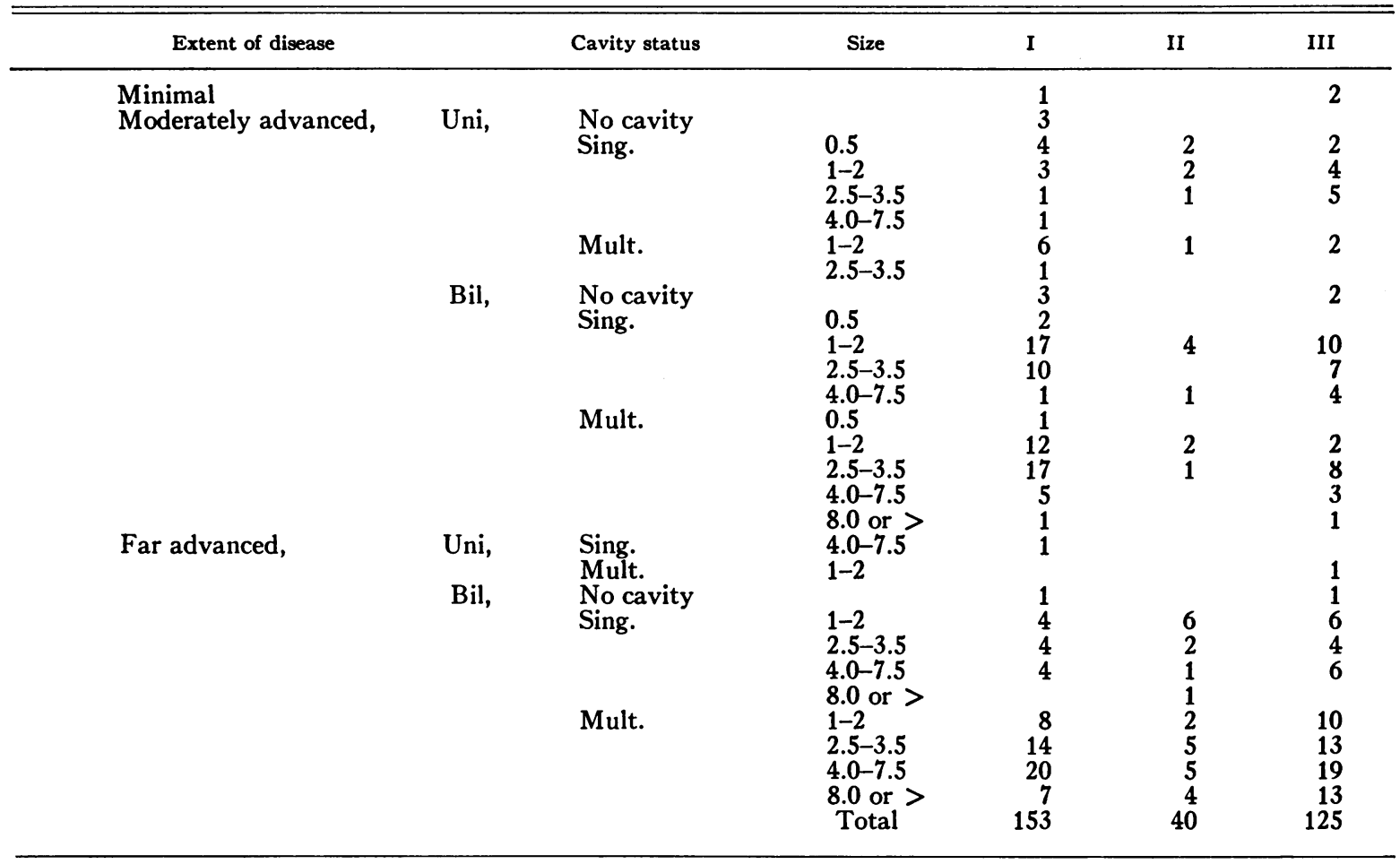

into three categories (Table V). Group I patients were excreting streptomycin-susceptible, isoniazid-susceptible populations of tubercle bacilli. Group II patients were excreting either streptomycin-resistant, isoniazid-susceptible or streptomycin-susceptible, isoniazid-resistant populations. Group III patients were excreting streptomycinand isoniazid-resistant populations. All patients of Groups II and III (except possibly one) who were excreting isoniazid-resistant populations of tubercle bacilli gave histories of at least three weeks' previous treatment with isoniazid or its chemical derivatives. Similarly, all, except four patients, who were excreting streptomycinresistant populations gave histories of previous streptomycin or dihydrostreptomycin treatment.

These three groups were similar with respect to age, sex, and race (Table V). Comparison of the members of these three groups of patients by roentgenographic characteristics of disease revealed that they were suffciently comparable for the purposes of this study (Table VI).

F. Basic chemotherapeutic regimen. This consisted of streptomycin sulfate (Squibb), 1 to $2 \mathrm{Gm}$. daily (20 mg. per $\mathrm{Kg}$. per day or more in those patients who had low streptomycin serum levels), by the intramuscular route in a single dose, for at least 90 days. Streptomycin was not discontinued until the sputum was negative on smear and culture of the concentrate. Isoniazid ( $\mathrm{Ny}$ drazid@, Squibb), 16 or more $\mathrm{mg}$. per $\mathrm{Kg}$. per day, was administered orally for at least 18 months. Isoniazid was given in two equal doses each day. Pyridoxine hydrochloride (Squibb), 50 to $100 \mathrm{mg}$. per day, was also given orally for 18 months. Pyridoxine was included in this regimen to reduce the incidence of significant isoniazid neuropathy (15). It should be emphasized that following termination of streptomycin, the isoniazid and pyridoxine were continued alone.

During the period covered in this report, the effect of short-term, 21 day chemotherapy with pyrazinamide (2.5 $\mathrm{Gm}$. per day) and cortisone (100 mg. per day), to be followed at once by the basic regimen, was under investigation in 37 of these patients. So far no significant difference in results of this strictly randomized study has been observed.

Treatment with the basic high dosage regimen was

TABLE VII

Basic chemotherapeutic regimen adaptations

\begin{tabular}{ccc}
\hline \hline Group & Drug-susc. & \multicolumn{1}{c}{ Chemotherapy } \\
\hline I & SM-S/INH-S & $\begin{array}{c}\text { Basic high dosage regimen } \\
\text { (SM/INH)* }\end{array}$ \\
II & SM-R/INH-S & $\begin{array}{l}\text { INH/PAS } \\
\text { SM-S/INH-R }\end{array}$ \\
III & SM-RAS /INH-R & $\begin{array}{c}\text { VM, PZA, PAS, TTC, SM, } \\
\text { and INH* }\end{array}$ \\
& &
\end{tabular}

* Para-aminosalicylic acid (PAS) or para-aminobenzoic acid (PABA) added if serum INH level $<0.4 \mu \mathrm{g}$. per $\mathrm{ml}$. 
TABLE VIII

Significant drug reactions

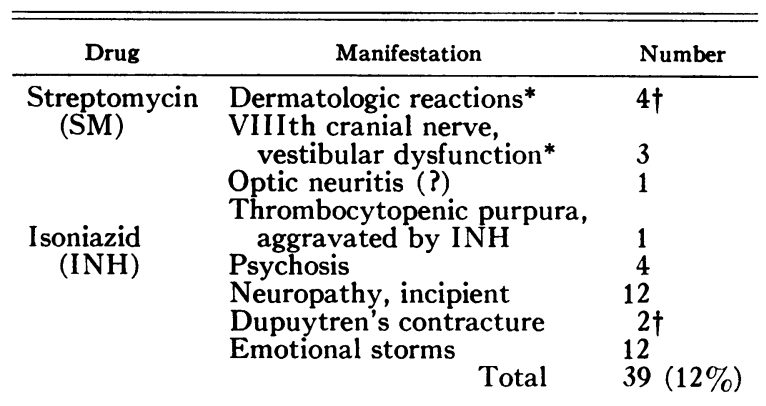

* Severe reactions.

$\uparrow$ Chemotherapy continued with steroids.

considered to be appropriate for the Group I patients (Table VII). Half of Group II patients were excreting streptomycin-resistant, isoniazid-susceptible organisms and isoniazid plus para-aminosalicyclic acid (NaPAS, 12 Gm. per day) was appropriate. The other half of Group II were excreting streptomycin-susceptible, isoniazid-resistant tubercle bacilli and daily streptomycin, 1 to $2 \mathrm{Gm}$. for at least 90 days with para-aminosalicylic acid (NaPAS, $12 \mathrm{Gm}$. per day) plus isoniazid, was deemed appropriate chemotherapy.

Patients in Group III were treated with viomycin, pyrazinamide, para-aminosalicylic acid, tetracycline and streptomycin in a variety of combinations with isoniazid. Most patients in Groups I and III who had active isoniazid levels less than $0.4 \mu \mathrm{g}$. per $\mathrm{ml}$. were also given paraaminosalicylic acid or para-aminobenzoic acid to raise the isoniazid level. Isoniazid was included in every regimen because it was considered appropriate to prevent backmutation. Both animal experimentation (16) and in vitro studies (17) have proven that back-mutation to isoniazid-susceptibility can occur.

After initiation of chemotherapy, all patients, except those with severely restricted cardiopulmonary function, were out of bed for 10 to 12 hours daily.

Collapse procedures and/or resection surgery were performed on Group II and III patients when deemed appropriate, but not on Group I patients until four months after conversion.

G. Drug reactions. Serious drug reactions with the high dosage regimen incorporating pyridoxine have been infrequent (Table VIII). Significant reactions to streptomycin or isoniazid occurred in 12 per cent of our patients. The specific drug was permanently discontinued only for those few patients manifesting severe vestibular nerve reactions, optic neuritis, aggravation of thrombocytopenic purpura or psychosis. No apparent change in clinical response to chemotherapy was observed in these patients following termination of the offending drug.

\section{RESULTS}

There was a striking difference in roentgenographic inprovement estimated separately from changes in cavity status between Group I and Groups II and III after four months of chemotherapy, and this became more marked during the five to eight month period (Table II). Two of the patients in Group III were subjected to thoracoplasty within 60 days of the start of chemotherapy, and so do not appear in this analysis. Similarly, three Group II patients and 24 Group III patients were eliminated from X-ray evaluation by the application of collapse procedures or surgical resection during the five to eight month period.

In 51 of the Group I patients with demonstrable cavitation on admission, no cavities could be detected on routine $\mathrm{X}$-rays and tomograms by the end of five to eight months of chemotherapy (Table III). As a further evaluation, analysis of the changes in cavity status confirmed the superior response to chemotherapy of Group I.

One hundred and fifty-two Group I patients had sputum conversion to negative by the end of the sixth month of chemotherapy (Table I). No drug-resistant cultures were obtained from these patients prior to conversion. However, there was one chemotherapeutic failure, a 48 year old white man with far-advanced, bilateral cavitary disease. $\mathrm{He}$ had been treated with isoniazid, $300 \mathrm{mg}$. per day, and para-aminosalicylic acid, $12 \mathrm{Gm}$. per day, three days before admission to this hospital. The tubercle bacilli proved to be susceptible to streptomycin and isoniazid. His serum isoniazid level at six hours following a $4 \mathrm{mg}$. per $\mathrm{Kg}$. test dose was $1.2 \mu \mathrm{g}$. per $\mathrm{ml}$. His serum streptomycin level at six hours after a $20 \mathrm{mg}$. per $\mathrm{Kg}$. test dose was $20 \mu \mathrm{g}$. per $\mathrm{ml}$. Both levels can be considered adequate for optimal antimicrobial effect. His sputum became negative on smear and culture in less than 12 weeks of chemotherapy with isoniazid, $16 \mathrm{mg}$. per $\mathrm{Kg}$. per day, and streptomycin, $20 \mathrm{mg}$. per $\mathrm{Kg}$. per day. However, six weeks later his sputum suddenly reverted to positive with tubercle bacilli simultaneously resistant to both streptomycin and isoniazid; his sputum cultures remained positive. ${ }^{2}$

2 The possibility that this was the result of exogenous reinfection was considered. Survey of all hospitalized patients excreting organisms resistant to streptomycin (SM) and isoniazid revealed only one likely candidate. However, the organisms from that patient were highly resistant to streptomycin, $16 \mu \mathrm{g}$. per $\mathrm{ml}$., while the or- 
TABLE IX

Cumulative bacteriologic conversion

(collapse procedures and resection

in addition to chemotherapy)

\begin{tabular}{rrrrrrr}
\hline \hline Group & Total & $\begin{array}{r}1-4 \\
\text { Mos. }\end{array}$ & & $\begin{array}{r}5-8 \\
\text { Mos. }\end{array}$ & $\begin{array}{r}9-12 \\
\text { Mos. }\end{array}$ \\
\hline I & $(153)$ & 127 & $(153)$ & 152 & $(142)$ & 141 \\
II & $(40)$ & 13 & $(40)$ & 19 & $(39)^{*}$ & 21 \\
III & $(125)$ & 19 & $(125)$ & 33 & $(107)^{*}$ & 39
\end{tabular}

* None of Group I was subjected to collapse or resection until at least four months after conversion. Losses shown are due to early discharge.

These results with chemotherapy alone for Group I patients are strikingly different from those of both Groups II and III. If the Group II patients whose sputum became converted to negative concomitantly with collapse procedures or resection surgery were considered together with those achieving the converted state by chemotherapy alone, the total conversions by the end of one year would be only slightly more than half of the cases (Table IX). Similarly, only about one-third of the Group III patients became converted to the sputum negative state by the end of one year of treatment.

\section{Follow-up observations on Group I patients}

Follow-up observations have been completed on 90 per cent of the first 113 Group I patients who were treated for at least six months. At the time of this study, these patients had been observed for an average of two years since the start of chemotherapy, ranging from 18 to 33 months. Fifty-three of these patients were still on chemotherapy at the time of follow-up study, and 51 had terminated all antimicrobial drugs. The average period of time between termination of chemotherapy and the mailing of the most recent follow-up questionnaire was five and four-tenths months, ranging from one to 15 months. Of those patients whose chemotherapy was discontinued, only one patient has had a relapse, both bacteriologic and roentgenographic. This 39 year old white man had partial gastrectomy, choledocoduodenostomy and gastroenterostomy prior to the diagnosis of tuberculosis. He was admitted to hospital with moderately advanced, unilateral disease and multiple cavities, 1 to $2 \mathrm{~cm}$. in greatganisms from the failure were fully susceptible to $8 \mu \mathrm{g}$. per $\mathrm{ml}$. even though highly resistant to $2 \mu \mathrm{g}$. SM per $\mathrm{ml}$. est internal dimension. At that time his electrocardiogram revealed evidence of old anterior myocardial infarction. He was treated with the basic high dosage regimen to which was added para-aminosalicylic acid to elevate the serum level of isoniazid. Early during this hospitalization, he suffered another myocardial infarction, and was placed on strict bed rest. He complained bitterly of para-aminosalicylic acid gastrointestinal irritation, and was unable to accept this medication regularly even though it was needed to elevate the serum isoniazid level. Resection of the cavitary disease was considered necessary, but surgery was postponed indefinitely because of the cardiac status. The patient left the hospital, discontinued all drugs in the seventh month of chemotherapy, and six months later he was readmitted to our hospital excreting streptomycin-susceptible, paraaminosalicylic acid-susceptible, catalase-positive, isoniazid-resistant organisms in his sputum. To date this is the only known relapse among the 153 Group I patients. ${ }^{3}$

\section{DISCUSSION}

The results of serum assays for antimicrobiallyactive streptomycin and isoniazid have suggested that conventional dosage could not be relied upon to insure adequate delivery of sterilizing concentrations to susceptible tubercle bacilli in chemotherapy of pulmonary tuberculosis. Therefore, a chemotherapeutic regimen was designed combining high dosage of streptomycin with high dosage of isoniazid. This high dosage regimen was administered to all patients excreting streptomycinsusceptible, isoniazid-susceptible tubercle bacilli on admission. Six hour serum assays for streptomycin and isoniazid were performed on some of these patients in order to document the adequacy of these drugs.

${ }^{3}$ Since this report was submitted for publication another patient has suffered a bacteriologic relapse. Both relapse cases had several points of similarity. Both became bacteriologically negative prior to the start of chemotherapy, even though positive on smear and culture on admission. Both left the hospital shortly after six months of chemotherapy, and both discontinued chemotherapy against medical advice in the seventh month. This second patient relapsed 21 months after stopping medications. And, finally, these two relapses were the only patients in Group I who were treated with drugs for less than nine months. 
A few large groups have carried out extensive studies on the chemotherapy of pulmonary tuberculosis (18-21). Retrospective analysis of the results of these investigations of conventional drug treatment regimens has revealed that 10 to 20 per cent of previously untreated patients fail to achieve the state of bacteriologic negativity without collapse procedures or surgical resection. In vitro drug-susceptibility tests indicated that most of these failures of chemotherapy resulted from the emergence of drug-resistant mutant populations of tubercle bacilli. In spite of the fact that combined drug regimens were used in these studies, failure of combined chemotherapy employing conventional dosages frequently was manifested by the early emergence of mutants resistant to only one of the two drugs administered. Experiments performed in our laboratory have indicated that selection of mutants resistant to one drug on exposure to two drugs is a consequence of exposure to effective concentrations of that one drug plus ineffective (sub-inhibitory) concentrations of the companion drug; in effect, this is equivalent to exposure to only one drug although the single-drug-resistant mutants recovered are strikingly reduced in numbers (see Experiment No. 2, in the first report of this series).

It seemed reasonable to postulate that increasing the dosage of each drug should largely eliminate such evidences of inadequate delivery of drugs as the emergence of organisms resistant to one of the two drugs. Support for this hypothesis was found in the British Medical Research Council reports $(18,19)$ which indicated that streptomycin, $1.0 \mathrm{Gm}$. daily, combined with isoniazid, 200 mg. daily, gave results superior to streptomycin, $1.0 \mathrm{Gm}$. twice each week, plus the same dosage of isoniazid (200 mg. per day). Further support for this postulate was evident in a study by Biehl (22) who made a clinical comparison between streptomycin, $1.0 \mathrm{Gm}$. twice each week, combined with isoniazid, $5 \mathrm{mg}$. per $\mathrm{Kg}$. per day, and the same dosage of streptomycin $(1.0 \mathrm{Gm}$. twice each week) plus isoniazid, $20 \mathrm{mg}$. per $\mathrm{Kg}$. per day. The regimen including high dosage isoniazid combined with low dosage streptomycin $(2.0 \mathrm{Gm}$. per week) failed to prevent the emergence of isoniazid-resistant organisms. Viewed in the light of these studies, the excellent results obtained in Group I patients could have been anticipated.
The results obtained by application of the high dosage isoniazid-high dosage streptomycin basic regimen to the chemotherapy of Group I patients are superior to the results reported by other investigators with the exception of Ross, Horne, Grant and Crofton $(23,24)$. It can be contended that this superiority is attributable to factors other than chemotherapeutic. The type of patient material in terms of anatomic extent of disease, number and size of cavities, and duration of active disease, for example, may be less challenging among patients accepted for admission to $\mathrm{Na}$ tional Jewish Hospital. There may be other important variables, such as altitude $(5,300 \mathrm{ft}$.), or the complex advantages of hospitalization per se which would favor the obtaining of such results. However, our experience prior to October of 1954 with chemotherapeutic regimens which did not include both high dosage of isoniazid and high dosage of streptomycin provided adequate evidence, in our opinion, that such unidentified variables were not operating in these studies. For example, between January of 1953 and October of 1954, 43 adult patients excreting typical tubercle bacilli susceptible to both streptomycin and isoniazid were treated with streptomycin, $1.0 \mathrm{Gm}$. intramuscularly every third day, combined with isoniazid, 8 or more mg. per $\mathrm{Kg}$. per day, for at least four months before collapse procedures or surgical resection. Thirty-one (72 per cent) of these patients became bacteriologically negative by Day 120 of chemotherapy, but 11 (26 per cent) were chemotherapeutic failures by virtue of the emergence of isoniazid-resistant organisms (25). Thus, our experiences at this institution prior to the initiation of the high dosage regimen described here were quite comparable to the experiences of other investigators employing similar chemotherapeutic regimens.

With regard to the results reported by Crofton and his associates, it should be pointed out that two uncontrolled variables render their studies incomparable with the Group I experiences described here. First, they have reported that all three drugs (streptomycin, isoniazid and para-aminosalicylic acid) were often used during the first six to eight weeks of chemotherapy, i.e., until the results of drug-susceptibility studies became available (26). Para-aminosalicylic acid is known to decrease the rate of metabolic inactivation of iso- 
niazid $(2,3)$, and, therefore, can obscure the role played by this phenomenon in determining the effectiveness of chemotherapy with isoniazid. Second, other therapeutic measures were taken (pneumoperitoneum and so forth) ad lib., in addition to chemotherapy, before four months after bacteriologic conversion of the sputum to negative.

The poor results of antimicrobial therapy alone in patients of Group III were not surprising (Table I). They point up the need for additional effective chemotherapeutic agents for tuberculosis. On the other hand, the 47 per cent conversion rate (16 patients converted out of 34 treated for nine to 12 months without collapse procedures or surgery) for patients in Group II may seem unexpectedly low. However, many of the patients in this group were excreting populations of tubercle bacilli which were resistant to paraaminosalicylic acid as well as to either streptomycin or isoniazid on admission to hospital. Therefore, in effect, several of these patients received the benefit of only single-drug treatment during the period of this study.

It has been customary for some clinicians to reserve "one good drug" for use at the time of surgery. These results indicate that it would be better to strive for optimal chemotherapeutic results from the initiation of treatment.

The success observed on application of the appropriate basic high dosage regimen in patients excreting drug-susceptible tubercle bacilli seems to eliminate any doubt as to the clinical importance of delivering adequate concentrations of at least two antimicrobial drugs in vivo. As was implied in the first report of this series (1), there is a definite, but very low, incidence of mutant forms of tubercle bacilli which are simultaneously resistant to both streptomycin and isoniazid. Thus, there will be a definite incidence of chemotherapeutic failure on any two-drug regimen. Just as adequate twodrug regimens markedly decrease the incidence of chemotherapeutic failure manifested by the emergence of one-drug-resistant mutant populations, so should adequate regimens of three or more drugs decrease the incidence of chemotherapeutic failure manifested by the emergence of two-drug-resistant mutant populations. It seems fair to assume that the one instance of double mutation to resistance to both isoniazid and streptomycin which occurred in these studies could have been prevented had a third drug, i.e., para-aminosalicylic acid, been added to his therapeutic regimen before the twelfth week of chemotherapy.

The present study constitutes a relatively shortterm evaluation of chemotherapy of pulmonary tuberculosis in adults. Resting bacterial cells which escape sterilization by virtue of being physiologically insusceptible to the action of streptomycin or isoniazid remain a threat able to initiate an exacerbation of the disease months or even years later (27). Therefore, final evaluation of any approach to the chemotherapy of tuberculosis requires a long period of follow-up observation.

Among 133 patients in Group I who presented roentgenographic evidence of cavitary disease on initiation of chemotherapy and who remained in hospital at least four months after the date of bacteriologic conversion to negative, 66 (50 per cent) had persistence of cavitation ("open cavity healing" by clinical criteria). This is the highest incidence of "open cavity healing" reported in the literature. It can fairly be attributed to the avoidance of those measures-strict bed rest, and pulmonary collapse procedures-which, in our opinion (28), are in serious conflict with the purposes of appropriate and effective antimicrobial chemotherapy.

For patients treated with conventional drug regimens plus bed rest, important unfavorable prognostic significance has been attached to the persistence of roentgenographically-visible cavitation even when it is accompanied by the absence of acid-fast bacilli from the sputum (29). On the other hand, more recently, evidence has been presented by some investigators $(30,31)$ that the association of open, air-filled cavities with persistently negative sputum bacteriology after more effective protocols of chemotherapy does not have unfavorable significance. It will be interesting to determine whether patients treated under the high dosage combined drug regimen will show relapse rates lower than those which have been observed on previous modes of therapy. Results obtained from bacteriological studies on surgically resected pulmonary lesions from patients in Group I of this study provide corroborative evidence that this may, indeed, be anticipated (32).

In retrospect, the observations on the variations in the metabolic disposition of isoniazid and on the six hour serum levels after streptomycin, 20 
mg. per Kg., indicate that many of the Group I patients might have responded as favorably to chemotherapy employing lower dosages of these drugs. Indeed, in view of the significant incidence of drug reactions (12 per cent) in our experience with the high dosage regimen for all patients, it seems that routine high dosage imposes an unnecessary risk. Thus, the best approach should be one in which dosages of appropriate drugs are adjusted according to the results of specific pharmacologic assays.

The minimal immediate chemotherapeutic failure and the low early relapse rate in Group I patients, on the one hand, and the high failure rate in the Group II and Group III patients, on the other hand, provide evidence of the clinical value of the drug-susceptibility tests employed in these studies for predicting response to chemotherapy with these drugs.

Ninety-nine per cent of the patients who excreted streptomycin-susceptible, isoniazid-susceptible tubercle bacilli at the start of chemotherapy at this hospital achieved sputum conversion on the high dosage regimen without collapse or surgery, or strict bed rest. Microbiologic serum assay allowed prompt discovery and correction of isoniazid dosages in those few individuals who might have had inadequate drug with the unmodified regimen. The general principles of primary chemotherapy of tuberculosis upon which the treatment of the Group I patients was based have been outlined previously (28). The very low chemotherapeutic failure rate observed in such patients in this study confirms our previous opinion (28) that the drug-treatment failures of conventional chemotherapy are largely due to inadequate dosage of drugs or indiscriminate combinations of therapeutic measures.

\section{SUMMARY}

Three hundred eighteen adult patients with bacteriologically proved pulmonary tuberculosis due to typical tubercle bacilli were admitted consecutively to the National Jewish Hospital at Denver between October 1, 1954, and June 1, 1957, and were treated for at least six months. Of these, 153 were excreting organisms which were susceptible to both streptomycin and isoniazid. These patients were subjected to a high dosage streptomycin, high closage isoniazid chemo- therapeutic regimen. The sputa of 152 of the patients excreting populations of tubercle bacilli which were streptomycin- and isoniazid-susceptible became bacteriologically converted to negative by the end of the sixth month of chemotherapy. None of these 152 patients excreted drug-resistant organisms prior to conversion. There was one early chemotherapeutic failure, as manifested by the failure to achieve conversion and by the emergence of double-drug-resistant mutants. There has also been one bacteriologic and roentgenographic relapse.

Two other groups of patients, those who were already excreting drug-resistant organisms on admission to hospital, were studied for comparison: those excreting tubercle bacilli resistant to one drug, and those with organisms resistant to two drugs. Neither group demonstrated impressive response to chemotherapy. These results established the value of the special drug-susceptibility testing techniques employed for predicting the clinical response to treatment with streptomycin or isoniazid.

The theoretical and practical consequences of these studies were discussed.

\section{REFERENCES}

1. Cohn, M. L., Middlebrook, G., and Russell, W. F., Jr. Combined drug treatment of tuberculosis. I. Prevention of emergence of mutant populations of tubercle bacilli resistant to both streptomycin and isoniazid in vitro. J. clin. Invest. 1959, 38, 1349.

2. Mandel, W., Cohn, M. L., Russell, W. F., Jr., and Middlebrook, G. Serum isoniazid levels and catalase activities of tubercle bacilli from isoniazidtreated patients. Amer. J. med. Sci. 1957, 233, 66.

3. Mandel, W., Heaton, A. D., Russell, W. F., Jr., and Middlebrook, G. Combined drug treatment of tuberculosis. II. Studies of antimicrobially-active isoniazid and streptomycin serum levels in adult tuberculous patients. J. clin. Invest. 1959, 38, 1356.

4. Mitchell, R. S., Riemensnider, D. K., Harsch, J. R., and Bell, J. C. New information on the clinical implications of individual variations in the metabolic handling of antituberculous drugs, particularly isoniazid in Transactions of the 17th Conference on the Chemotherapy of Tuberculosis. Memphis, Tenn., 1958, vol. 17, p. 77.

5. Russell, W. F., Jr., and Dye, W. E. High dosage isoniazid plus daily streptomycin in the chemotherapy of pulmonary tuberculosis: A pilot study of 46 highly selected cases of drug-susceptible pul- 
monary tuberculosis including comparison with similar case material from the fifteenth conference V.A.-A.F. data in Transactions of the 16th Conference on the Chemotherapy of Tuberculosis. St. Louis, Mo., 1957, vol. 16, p. 91.

6. Kass, I., Russell, W. F., Jr., Heaton, A., Miyamoto, T., Middlebrook, G., and Dressler, S. H. Changing concepts in the treatment of pulmonary tuberculosis. Ann. intern. Med. 1957, 47, 744.

7. Russell, W. F., Jr., Kass, I., Heaton, A. D., Dressler, S. H., and Middlebronk, G. Further experiences with high dosage isoniazid plus daily streptomycin in the chemotherapy of pulmonary tuberculosis in Transactions of the 17th Conference on the Chemotherapy of Tuberculosis. Memphis, Tenn., 1958, vol. 17, p. 71.

8. Middlebrook, G., Cohn, M. L., and Schaefer, W. B. Studies on isoniazid and tubercle bacilli. III. The isolation, drug-susceptibility, and catalase-testing of tubercle bacilli from isoniazid-treated patients. Amer. Rev. Tuberc. 1954, 70, 852.

9. Middlebrook, G., and Cohn, M. L. Bacteriology of tuberculosis. Amer. J. publ. Hlth 1958, 48, 844.

10. Schaefer, W. B., Cohn, M. L., and Middlebrook, G. The roles of biotin and carbon dioxide in the cultivation of Mycobacterium tuberculosis. J. Bact. 1955, 69, 706.

11. National Tuberculosis Association. Diagnostic Standards and Classification of Tuberculosis. New York, National Tuberculosis Association, 1955.

12. Mandel, W., Cohn, M. L., Russell, W. F., Jr., and Middlebrook, G. Effect of para-aminosalicylic acid on serum isoniazid levels in man. Proc. Soc. exp. Biol. (N. Y.) 1956, 91, 409.

13. Morse, W. C., Curry, F. J., Morse, P. Z., Chambers, J. S., and Lincoln, A. F. Effect of oral PAS on biologically active isoniazid serum levels in Transactions of the 15th Conference on the Chemotherapy of Tuberculosis. St. Louis, Mo., 1956, vol. 15, p. 283.

14. Middlebrook, G. Diagnostic and biological problems of isoniazid-resistant tubercle bacilli. Bull. int. Un. Tuberc. 1956, 26, 179.

15. Carlson, H. B., Anthony, E. M., Russell, W. F., Jr., and Middlebrook, G. Prophylaxis of isoniazid neuropathy with pyridoxine. New Engl. J. Med. 1956, 255, 119.

16. Schmidt, L. H., Grover, A. A., Hoffmann, R., Rehm, J., and Sullivan, R. The emergence of isoniazidsensitive bacilli in monkeys inoculated with isoniazid-resistant strains in Transactions of the 17th Conference on the Chemotherapy of Tuberculosis. Memphis, Tenn., 1958, vol. 17, p. 264.

17. Middlebrook, G., and co-workers. Unpublished data.

18. Medical Research Council Isoniazid Trial: Report No. 4. Emergence of bacterial resistance in pulmonary tuberculosis under treatment with isonia- zid, streptomycin plus P.A.S., and streptomycin plus isoniazid. Lancet 1953, 2, 217.

19. Various combinations of isoniazid with streptomycin or with P.A.S. in the treatment of pulmonary tuberculosis. Brit. med. J. 1955, 1, 435.

20. Livings, D. G. Discussion of data on X-ray change, bacteriology, cavity closure, and relapse in the consolidated tables on pulmonary tuberculosis, basic regimens in Transactions of the 14th Conference on the Chemotherapy of Tuberculosis. Atlanta, Ga., 1955, vol. 14, p. 385.

21. The effect of streptomycin on the emergence of bacterial resistance to isoniazid; a U. S. Public Health Service cooperative investigation. Amer. Rev. Tuberc. 1953, 67, 553.

22. Biehl, J. P. Emergence of drug resistance as related to the dosage and metabolism of isoniazid in Transactions of the 16th Conference on the Chemotherapy of Tuberculosis. St. Louis, Mo., 1957, vol. 16, p. 108.

23. Ross, J. D., Horne, N. W., Grant, I. W. B., and Crofton, J. W. Hospital treatment of pulmonary tuberculosis. A follow-up study of patients admitted to Edinburgh hospitals in 1953. Brit. med. J. 1958, 1, 237.

24. Crofton, J. "Sputum conversion" and the metabolism of isoniazid. Amer. Rev. Tuberc. 1958, 77, 869.

25. Russell, W. F., Jr., and Middlebrook, G. Persistent excretion of isoniazid-susceptible tubercle bacilli in Transactions of the 15 th Conference on the Chemotherapy of Tuberculosis. St. Louis, Mo., 1956, vol. 15 , p. 274.

26. Stewart, S. M. Virulence of tubercle bacilli recovered from patients treated with isoniazid. Amer. Rev. Tuberc. 1954, 69, 641.

27. Schaefer, W. B. The effect of isoniazid on growing and resting tubercle bacilli. Amer. Rev. Tuberc. 1954, 69, 125.

28. Russell, W. F., Jr., Dressler, S. H., and Middlebrook, G. Chemotherapy of tuberculosis. Advanc. intern. Med. 1956, 8, 221.

29. Bell, J. W. The problem of resection surgery for pulmonary tuberculosis in the noninfectious patient with persisting cavitary disease. Amer. Rev. Tuberc. 1956, 74, 169.

30. Ryder, J. B. Prognosis of persistent cavitation in sputum-negative cases of tuberculosis following long-term chemotherapy. Tubercle (Lond.) 1958, 39, 113.

31. Wilson, T. M., Doyle, L., and Gardiner, M. P. Open healing of tuberculous cavities. Results in 40 patients treated conservatively. Brit. med. J. 1958, $2,87$.

32. Heaton, A. D., Russell, W. F., Jr., Denst, J., and Middlebrook, G. Combined drug treatment of tuberculosis. IV. Bacteriologic studies on the sputum and resected pulmonary lesions of tuberculous patients. J. clin. Invest. 1959, 38, 1376. 